\section{Estudo \\ Ecibate}

em Cestão

Plamejamento
Revista Estudo \& Debate, Lajeado, v. 24, n. 2, 2017. ISSN 1983-036X

DOI: http://dx.doi.org/10.22410/issn.1983-036X.v24i2a2017.1178

\title{
O CONTROLE SOCIAL À LUZ DA GESTÃO SOCIAL: A ANÁLISE DO COMUDE DE SÁO VALÉRIO DO SUL/RS ${ }^{1}$
}

\author{
Adriano Fritzen ${ }^{2}$, Sérgio Luís Allebrandt ${ }^{3}$, Jenifer Friedrich Malaquias ${ }^{4}$, \\ Karla Letícia Morais da Silva ${ }^{5}$
}

\begin{abstract}
Resumo: Este estudo tem como objetivo realizar uma abordagem sobre a importância do controle social no processo democrático da sociedade brasileira, tendo como âmbito e lócus da pesquisa o Conselho Municipal de Desenvolvimento - Comude, do município de Sáo Valério do Sul. O mesmo consistiu em uma pesquisa teórica e conceitual sobre a evoluçáo de alguns conceitos, como gestão social e controle social, bem como se realizou entrevistas com o presidente do Comude e o prefeito municipal. Para análise e tratamento das informaçóes coletadas, como ferramenta metodológica foi empregado a hermenêutica de profundidade - HP de John B. Thompson (1995). A gestão municipal vem auxiliando na atuação e no escopo do Comude no nível municipal. Observa-se que existe transparência dos atos da administração pública local, no entanto isso ocorre principalmente pelo fato de que alguns dos Conselheiros serem servidores públicos. O Comude não possui espaço para discussão de temas ligados a transparência e ao combate a corrupção. Constata-se que o Comude acompanha e divulga políticas públicas na sua área de atuação, mas não realiza ações com o intuito de promover o controle social. O prefeito municipal destaca o envolvimento da sociedade civil nas açóes desempenhadas pelo Comude. Ressalta ainda que não se utiliza das proposiçóes discutidas pelo Comude. Um ponto negativo ressaltado pelo prefeito é que o Comude vincula sua atuação ao Programa de Participaçáo Popular e Cidadã do Estado do Rio Grande do Sul.
\end{abstract}

Palavras-chave: Controle Social. Gestão Social. Desenvolvimento Regional. Participação Popular. Corede. Comude.

1 Este estudo foi apresentado, em uma versão preliminar no Salão do Conhecimento, promovido pela Unijuí, no ano de 2016.

2 Mestrando em Desenvolvimento Regional pela Unijuí. Professor da Faisa Faculdades. E-mail: adrianofritzen@gmail.com.

3 Doutor em Desenvolvimento Regional pelo PPGDR/UNISC (2010), Mestre em Administração Empresarial pela EBAPE/FGV (2001), professor do DACEC da Unijuí. E-mail: allebr@unijui.edu.br.

4 Bolsista PROBIC-FAPERGS, aluna do Curso de Administração da Unijuí. E-mail: jenny.malaquias@hotmail.com.

5 Ex-bolsista PROBIC-FAPERGS (2015), aluna do curso de Administração da Unijuí. E-mail: karla.oi@bol.com.br. 


\title{
SOCIAL CONTROL BASED ON THE SOCIAL MANAGEMENT: THE ANALYSIS OF THE COMUDE OF SÃO VALÉRIO DO SUL/RS
}

\begin{abstract}
The objective of this study is approach the importance of social control in the democratic process in Brazilian society, having as the scope and locus of the research the Municipal Development Council - Comude, in the municipality of Sáo Valério do Sul. This paper consisted of a research theoretical and conceptual about the evolution of some concepts, such as social management and social control, as well as interviews with the Comude president and the municipal mayor. For the analysis and treatment of the information collected, as a methodological tool was used depth hermeneutics - HP of John B. Thompson (1995). Municipal management has been helping in the performance and scope of Comude at the municipal level. It is observed that there is transparency of the acts of the local public administration, however this is mainly due to the fact that some of the Councilors are public servants. In this Comude does not have space for discussion of issues related to transparency and the fight against corruption. It can be observed that Comude follows and disseminates public policies in its area of activity, but does not carry out actions with the purpose of promoting social control. The mayor emphasizes the involvement of civil society in the actions carried out by Comude. It should be noted that the propositions discussed by Comude are not used. A negative point highlighted by the mayor is that Comude links its work to the Program of Popular Participation and Citizen of the State of Rio Grande do Sul.
\end{abstract}

Keywords: Social Control. Social Management. Regional Development. Popular Participation. Corede. Comude.

\section{INTRODUÇÁO}

O controle social sobre o desenvolvimento regional, o qual constitui tema deste estudo, é entendido como aquele exercido por meio da participação do cidadão sobre as açóes do Estado que resultam no desenvolvimento regional.

O controle social é abordado à luz da gestão social, considerada um paradigma em construção, sendo trabalhado principalmente a partir do final dos anos 80 do século 20, por diferentes autores, como Tenório (1998, 2005, 2008, 2012a, 2012b, 2016), Fischer (2006), Cançado (2012), França Filho (2008), Kliksberg (1988, 1989), Esquivel-Corella (2004, 2005), Singer (1999), Paula (2005a, 2005b), Allebrandt (2002, 2010, 2016).

A experiência do Conselho Regional de Desenvolvimento - Corede, no estado do Rio Grande do Sul, inicia-se em 1991 "o processo de criação dos Coredes, ainda que a sua institucionalização legal aconteça apenas em 1994, pela Lei 10.283 de 17 de outubro e sua regulamentação pelo Decreto 35.764 de 29 de dezembro do mesmo ano, já no final do Governo Collares” Allebrandt e Siedenberg (2011, p. 262).

Já no âmbito municipal, Allebrandt e Siedenberg (2011, p. 263) complementam que "ainda que alguns conselhos municipais de desenvolvimento (Comudes) tenham sido criados no início da década de 1990 ou até antes, a grande maioria dos municípios criou os seus Comudes a partir de 2003”.

No que tange ao entendimento dos Coredes, Büttenbender, Siedenberg e Allebrandt (2011, p. 313)

os Coredes devem ser entendidos como fóruns regionais de discussão sobre estratégias, políticas e açóes que visam o desenvolvimento regional, constituídos como pessoas jurídicas de direito privado, organizados sob a forma de associaçôes civis sem fins lucrativos. 
Portanto, os Coredes constituem-se em importantes espaços públicos nos quais acontecem processos de discussão e deliberação, de assuntos relacionados com a temática do desenvolvimento local e regional. Deste modo, utiliza-se os Coredes e os Comudes como lócus desta pesquisa, pela sua importância nos processos participativos na sua área de atuaçấo.

O objetivo central deste estudo consiste em analisar as dinâmicas do Conselho Municipal de Desenvolvimento - Comude de São Valério do Sul/RS, utilizando a categoria controle social da matriz de categorias e critérios de análise de controle social.

Desta forma, este estudo tem como finalidade contribuir com a construção do paradigma da gestão social, observando a atuação nos processos participativos de discussão e deliberação do Comude, relacionados a temática do desenvolvimento local e regional.

Além desta introdução, este estudo divide-se nos seguintes itens: uma breve revisão teórica dos conceitos de gestão e controle social, os procedimentos metodológicos utilizados, a apresentação e discussáo dos resultados encontrados pela pesquisa realizada, em que apresenta-se uma breve caracterização do lócus da pesquisa e apresenta-se a análise e discussão dos resultados em conformidade com a categoria controle social, finalizando-se com as consideraçóes finais e as referências utilizadas neste estudo.

\section{REFERENCIAL TEÓRICO}

Neste capítulo, serão apresentados alguns dos referenciais utilizados como base teórica para a elaboração deste estudo, a priori abordam-se as concepçôes de gestáo social e controle social.

\subsection{Gestão social}

O conceito de gestão social vem sendo muito utilizado nas últimas décadas, sendo considerada por alguns autores como um paradigma em construção ${ }^{6}$, que se contrapóe ao conceito de gestão estratégica.

As discussōes no tocante a sociedade estão calcadas na relação entre Estado-sociedade e capital-trabalho. O conceito de gestão social é construído por Tenório a partir de uma inversão destes termos, propositalmente, passando para sociedade-Estado e trabalho-capital (TENÓRIO, 2016).

Sobre esta inversão destes termos, Tenório (2016, p. 16) argumenta que

Aparentemente esta mudança de posição dos temas não contribui, substantivamente, para uma análise dos fenômenos políticos, sociais e econômicos por eles gerados. Ao tomar como premissa, no entanto, que o estudo deve partir da ótica da sociedade e da ótica do trabalho, acreditamos mudar o enfoque de quem deve ser o protagonista no processo dessas relaçôes - a cidadania.

6 Conforme Boullosa apud Cançado, Pereira e Tenório (2015, p. 105) "a Gestáo Social tem um caráter in progress". 
Desta forma as relaçôes sociais teriam um maior protagonismo para a cidadania, pois as relaçóes sociais ocorrem a partir da sociedade e do trabalho. Complementarmente, Tenório (2016, p. 38) descreve que a "gestáo social é o processo intersubjetivo que preside a ação da cidadania tanto na esfera privada quanto na esfera pública".

Contrapondo-se a gestão estratégica, a gestão social na concepção de Tenório (2008, p. 24-25) "tenta substituir a gestão tecnoburocrática, monológica, por um gerenciamento mais participativo, dialógico, no qual o processo decisório é exercido por meio de diferentes sujeitos sociais".

Desta forma, a gestão social é orientada pela racionalidade comunicativa habermasiana, pois

\begin{abstract}
No processo de gestão social, acorde com o agir comunicativo - dialógico, a verdade só existe se todos os participantes da ação social admitem sua validade, isto é, verdade é a promessa de consenso racional, ou a verdade não é uma relação entre indivíduo e a sua percepção do mundo, mas sim um acordo alcançado por meio da discussão crítica, da apreciação intersubjetiva (TENÓRIO, 2016, p. 29).
\end{abstract}

No entanto, Fischer et al. (2006, p. 796) "a gestão adjetivada como social orienta-se para a mudança e pela mudança, seja de microunidades organizacionais, seja de organizaçóes com alto grau de hibridizaçáo, como são as interorganizaçôes atuantes em espaços territoriais micro ou macroescalares".

A gestâo social para Paula (2005b, p. 45), é "entendida como uma ação política deliberativa, na qual o indivíduo participa decidindo seu destino como pessoa, eleitor, trabalhador ou consumidor". A participação do cidadão de forma deliberativa é fundamental para a definição das situaçóes que se relacionam com o futuro da sociedade.

Cançado, Pereira e Tenório (2015, p. 130) argumentam que "se a decisão é coletiva efetivamente, a coerção é estranha ao processo e o entendimento (e não a negociação) deve ser seu caminho. Emerge aqui a dialogicidade como outra característica da Gestão Social". Portanto, a gestão social é baseada na decisão coletiva sem coerçâao, tendo a dialogicidade como característica inerente ao processo.

Resumidamente, a gestão social consiste em uma proposta de processo democrático de decisão, no qual deve existir a possibilidade de uma gestão participativa e deliberativa, ao contrário de um processo de implementação de políticas públicas com o intuito de atender demandas sociais. Outro fator importante para o processo de tomada de decisão é que o mesmo deve permitir a participaçâo de diferentes atores sociais, observando como finalidade precípua, que seja alcançado o bem comum para a sociedade (TENÓRIO, 2012a).

A gestão pública societal está pautada na gestão social e em uma concepçấo de democracia participativa e deliberativa, a qual segundo Paula (2005a, p. 159), a qual visa

Estabelecer uma gestão pública que não centraliza o processo decisório no aparelho do Estado e contempla a complexidade das relaçóes políticas, pois procura se alimentar de diferentes canais de participação, e modelar novos desenhos institucionais para conectar as esferas municipal, estadual e federal. 
Desta forma, a autora busca avançar na proposta de gestão social, sendo a mesma mais alinhada para as açóes realizadas pela gestão pública, propondo deste modo uma gestáo pública societal, baseada na democracia participativa e deliberativa.

\subsection{Controle social}

O papel da sociedade no que se refere ao controle social é o de exigir a prestação de contas dos governantes sobre suas açóes, bem como o poder de influenciar no ciclo de políticas públicas, desde a criaçáo e discussão da agenda, a elaboração e implementaçáo da política pública até a avaliação da política pública.

Tenório (2011, p. 84) argumenta que "colegiados com características de gestão compartilhada e de proposta deliberativa estaráo, explicitamente, impulsionando o controle social uma vez que a interação dos atores promove, entre os mesmos, um monitoramento coletivo".

O controle social, conforme de Gomes (2015, p. 903-904), se refere:

[...] a um controle ascendente, associado à responsividade e à responsabilização do governo em uma relação constante e não eleitoral com a sociedade. Isso implica para a sociedade, como nas eleições, o direito de exigir a prestação de contas no uso dos recursos, influenciar ou decidir sobre escolha das políticas públicas, fiscalizar o cumprimento de suas deliberaçóes e sancionar, entre outras prerrogativas. Tal controle pode ser empreendido de forma direta ou por meio de instâncias de representação distintas da representação parlamentar, como os conselhos gestores deliberativos.

Na concepção de Bergue (2012, p. 7), o controle social é

[...] uma relação dialógica. É um processo de aprendizagem, no qual, ao temo em que o cidadáo toma ciência de dados e informaçóes, demanda um conjunto de conceitos prévios que o autorize a conferir significado a esses elementos e o permita agir. Essa aprendizagem conduz o cidadáo a um novo patamar de conhecimento e de apropriação e comprometimento com os problemas públicos - outra condiçáo de cidadania. Entre as resultantes da açáo do controle social deve estar, também, o repensar político-institucional das organizaçôes que configuram a administração pública.

Para que ocorra o processo de participação popular com o intuito de promover assim açóes voltadas ao controle social, um fator importante é a existência e o fortalecimento da atuação dos espaços públicos, os quais possibilitam a participaçáo cidadá. Segundo Laisner e De Mario (2014, p. 625), os espaços públicos são importantes, pois

[...] dão voz a novos atores e temas, dão visibilidade ao conflito, permitindo que se reconheçam os interesses e opiniōes divergentes e propiciam aos seus participantes acesso à informação, conhecimento e poder. Trata-se da formação política de um cidadáo cuja identidade social e individual se constrói e se fortalece quando em relação com a instituiçâa.

Em síntese, para Serra e Carneiro (2012, p. 47), o controle social “[...] é a participação da sociedade no acompanhamento das escolhas de interesse público, verificação dos planos 
orçamentários de governos e das açóes da gestão pública, da execução de suas políticas, avaliando atos, cumprimento de objetivos, processos e resultados".

A participação popular e o controle social são formas de exercício da soberania popular, onde a primeira se refere ao poder político que contribui com a constituição das normas jurídicas estatais. Já o segundo trata do direito de controle exercido pelo cidadáo sobre as açóes do Estado, que logra proveito de normas previamente elaboradas com a finalidade de expor o Estado à submissão do cidadão (SIRAQUE, 2005).

Contribuindo nesta diferenciação entre participação popular de controle social, Tenório (2012b, p. 31) define que as "decisões tanto nos processos de implementação de políticas públicas - participaçáo popular - como nos casos em que os cidadãos desejem acompanhar ou avaliar o fazer da Administração Pública local - controle social”.

Diferencia-se, portanto, a participação popular, que acontece durante o processo de formulaçáo da política pública, já o controle social ocorre posteriormente a implementaçáo da política pública, pois ela tem como intuito acompanhar e fiscalizar a execução da mesma.

\section{PROCEDIMENTOS METODOLÓGICOS}

Neste estudo utiliza-se a hermenêutica de profundidade (HP), no enfoque utilizado por Thompson (1995, p. 363), sendo que o mesmo entende que a "hermenêutica da vida quotidiana é um ponto de partida primordial e inevitável do enfoque da HP”. Assim sendo, o enfoque da HP deve ser baseado na elucidação das formas simbólicas pela sua interpretaçáo e compreensão pelas pessoas na sua vida quotidiana.

Para a análise e interpretação dos dados, foi utilizada a categoria de análise controle social e seus critérios apresentados na Figural, incorporada pelo GPDeC à matriz de categorias e critérios de análise proposta por Tenório (2012a, 2012b) e Villela (2012). 
Figura 1: Matriz de categorias e critérios de análise de controle social

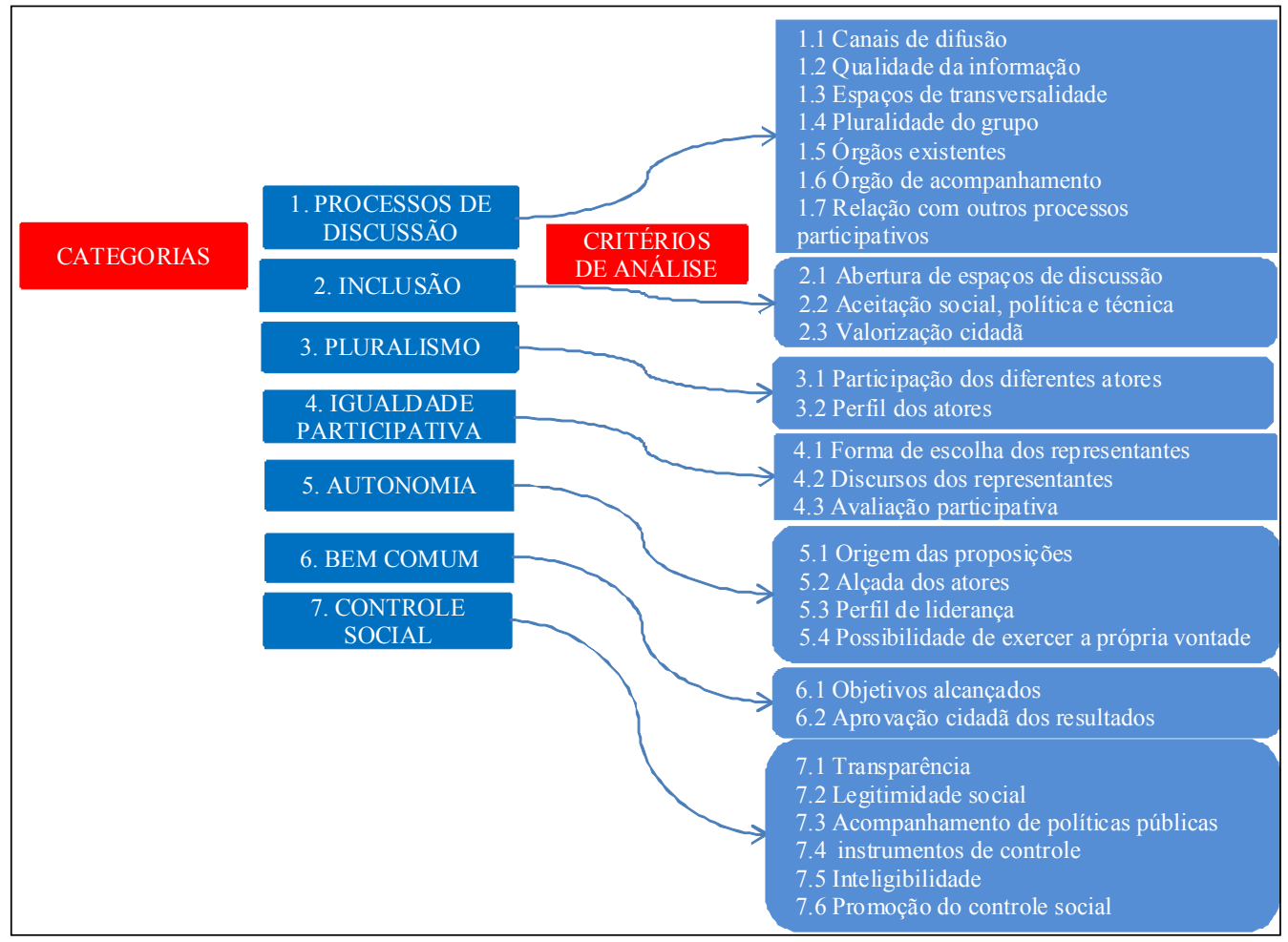

Fonte: Elaborado pelos autores a partir de Tenório (2012b), Villela (2012).

Esta matriz foi originalmente elaborada por Tenório (2012b) e Villela (2012), tendo sido acrescentado à matriz original a categoria 7: controle social e seus critérios, a partir de pesquisas e discussóes do Grupo Interdisciplinar de Estudos em Gestão e Políticas Públicas, Desenvolvimento, Comunicação e Cidadania (GPDeC), vinculado ao Programa de PósGraduação em Desenvolvimento Regional (PPGDR/Unijuí).

\section{RESULTADOS E DISCUSSÓES}

Neste capítulo, será apresentado uma breve caracterização do lócus escolhido para a realização desta pesquisa, bem como a análise e discussão das entrevistas realizadas com a presidente do Comude e o prefeito do município de São Valério do Sul.

\subsection{Caracterização do lócus}

Nesta seção, após uma breve caracterização do lócus do estudo, analisa-se a categoria controle social, que se divide em seis critérios de análise, que são os seguintes: transparência, legitimidade social, acompanhamento de políticas públicas, instrumentos de controle, inteligibilidade e promoção do controle social. 
O município estudado é o de São Valério do Sul, o qual está situado no Conselho de Desenvolvimento Regional (Corede) Celeiro, no noroeste do estado do Rio Grande do Sul. O município possui uma população de 3.067 habitantes em 2014, área aproximada de 108 $\mathrm{km}^{2}$, densidade demográfica 25,20 (FEE, 2014), e um IDH em 2010 de 0,642 (PNUD, 2013), conforme Quadro 1.

Quadro 1: População, área, IDH e PIB de São Valério do Sul

\begin{tabular}{|l|c|c|c|c|c|c|c|c|}
\hline Município & $\begin{array}{c}\text { População } \\
(2014)\end{array}$ & $\begin{array}{c}\text { Área } \\
\mathrm{KM}^{2}\end{array}$ & $\begin{array}{c}\text { Densidade } \\
\text { Demográfica }\end{array}$ & $\begin{array}{c}\text { Expectativa de } \\
\text { vida ao nascer } \\
(2010)\end{array}$ & $\begin{array}{c}\text { IDH } \\
2010\end{array}$ & $\begin{array}{c}\text { PIB } \\
\text { (2013) em } \\
\text { milhares } \\
\text { de R\$ }\end{array}$ & $\begin{array}{c}\text { PIB per } \\
\text { capita } \\
(2013)\end{array}$ & $\begin{array}{c}\text { Data de } \\
\text { Criaçáo }\end{array}$ \\
\hline $\begin{array}{l}\text { Sáo Valério } \\
\text { do Sul }\end{array}$ & 3.067 & 108,00 & 25,20 & 73,97 & 0,642 & $47.201,00$ & $17.207,65$ & $20 / 03 / 1992$ \\
\hline
\end{tabular}

Fonte: Elaborado pelos autores a partir de FEE, PNUD (2013)

O Corede Celeiro é um dos atuais 28 Coredes gaúchos, tendo sido criado em 2008, a partir do desmembramento do Corede Noroeste Colonial. Atualmente o mesmo é composto por 21 municípios, os quais todos possuem organizados os Conselhos Municipais de Desenvolvimento (Comudes).

O Comude de São Valério do Sul/RS foi instituído por meio da Lei Municipal no 443 , em $1^{\circ}$ de julho de 2003 . Esta Lei foi substituída posteriormente pela Lei Municipal $n^{\circ}$ 876, de 22 de junho de 2010.

O Comude é um espaço público que proporciona a possibilidade de discussão sobre temáticas relacionadas ao desenvolvimento local, do qual participam diversas entidades com o intuito de promover o desenvolvimento e melhorar a qualidade de vida da populaçáo no município. Os objetivos do Comude, de acordo com o artigo $2^{\circ}$ da Lei Municipal $n^{\circ}$ 876/2010, são a

Promoção do desenvolvimento local, harmônico e sustentado, através da integração das ações do poder público com as organizaçôes privadas, as entidades da sociedade civil organizada e os cidadáos, visando a melhoria da qualidade de vida da população, a distribuição harmônica e equilibrada da economia e a preservação do meio ambiente.

Coredes e Comudes podem ter uma atuação importante no processo de promoção do desenvolvimento local e regional, por meio do seu escopo, pela possibilidade de uma democracia deliberativa, frente a democracia representativa existente no Brasil atualmente.

Por esse motivo, está sendo realizada esta pesquisa no âmbito de todos os municípios do Corede Celeiro. Este artigo apresenta um recorte desta pesquisa, analisando aspectos do controle social a partir das entrevistas realizadas com o presidente do Comude e com o prefeito de São Valério do Sul.

A entrevista ao presidente do Comude do município de São Valério do Sul foi realizada no dia 06 de maio de 2016, e com prefeito foi realizada no dia 18 de julho de 2016 . As entrevistas foram transcritas e analisadas a partir da categoria controle social, conforme apresentado na matriz da Figura 1, item 7 controle social, e os seus respectivos critérios de 
análise que são: transparência, legitimidade social, acompanhamento de políticas públicas, instrumentos de controle, inteligibilidade e promoção do controle social.

\subsection{Análise da atuaçáo do Comude}

Esta seção analisa a entrevista realizada com a presidente do Comude de São Valério do Sul sob o enfoque da gestão social e do controle social. A análise neste estudo se restringe a categoria do controle social conforme proposto na Matriz de Categorias e critérios de Análise, conforme a Figura 1.

A presidente do Comude informou que participa das açóes desenvolvidas pelo mesmo por um período aproximado de cinco anos e seis meses do Conselho, sendo que o mesmo ocupa presidência a três anos e seis meses, aproximadamente.

A análise do critério transparência da matriz de categorias de análise, que informaçóes governamentais abertas aos cidadãos, propiciando o acesso as informações possibilitando uma maior fiscalização pela sociedade se torne um dos fatores relevantes constatados diz respeito ao acesso às informaçóes dos membros do Conselho. Os conselheiros dispóem de acesso privilegiado as informaçóes necessárias, pois alguns conselheiros são membros da administração pública, principalmente no nível local.

Esta situação pode ser confirmada pelo trecho da entrevista que "[...] em informaçóes, que muitas vezes os membros do conselho são servidores públicos, informaçōes desses servidores, se fosse conselho externo não teria informaçóes táo privilegiadas". Portanto, existem mecanismos que disponibilizam in formaçóes ao Conselho de forma privilegiada, mas isto ocorre pelo fato de que os conselheiros são membros da administraçáo local.

Tal situação poderá limitar a atuação do Comude a partir do momento em que os alterar a composiçáo de conselheiros, e estes náo forem membros do poder executivo local, ou não possuírem mais acesso as informações do setor público. A administração local poderia dispor de um canal de acesso às informaçôes pelos conselheiros, o que facilitaria a atuação dos mesmos.

O segundo critério de análise da matriz é a legitimidade social, que visa o reconhecimento da capacidade de atuaçáo do Conselho como promotor do controle social. Este critério analisa a importância do Comude no controle social do desenvolvimento regional.

Quando solicitado ao presidente se o Comude teria condiçôes de assumir o protagonismo no controle social, a entrevistada respondeu que "[...] ele [Comude] sozinho não. Dependeria de vários fatores, o conselho é só um meio participativo, mas não teria o poder de fazer isso sozinho". Deste modo, o Conselho necessitaria do auxílio de outros órgãos, entidades participativas para realizar açōes de promoção do controle social.

No critério legitimidade social ainda se verificou informaçóes sobre a percepção dos atores envolvidos no Conselho, os quais segundo a presidente do Comude "[...] deveriam ser, mas acho que não são".

Outra situação pesquisada no critério legitimidade social se refere a discussão no âmbito do Comude de assuntos vinculados a transparência e ao combate a corrupção, 
segundo o presidente do Comude não são discutidos temas relacionados a transparência e combate a corrupção. Por se tratar de um espaço público, o Comude poderia discutir assuntos relacionados ao combate a corrupçáo e transparência.

Para o critério acompanhamento de políticas públicas, o Conselho realiza análise e acompanhamento das políticas públicas relacionadas à temática do desenvolvimento local e regional. Mas restringe a sua atuação de acompanhamento das políticas públicas relacionadas ao orçamento participativo do Estado do Rio Grande do Sul.

$\mathrm{O}$ quinto critério de análise se refere aos instrumentos de controle. No Comude de São Valério do Sul não foi apresentado nenhum tipo de instrumento utilizado pelo Conselho com a finalidade de efetuar controle social do desenvolvimento regional.

Quanto ao quinto critério de análise que é a inteligibilidade, a qual se refere à capacidade de perceber e compreender as informaçóes. Constatou-se por meio da entrevista que as informaçóes acessadas ou disponibilizadas ao Conselho são de fácil compreensão e interpretação pelos conselheiros na percepção de seu presidente.

A inteligibilidade, principalmente quando se refere as informações, pode auxiliar no processo fiscalizatório por parte da sociedade civil, das açóes realizadas pelo poder público voltadas ao controle social.

Por último, o critério promoção do controle social investiga se o Comude tem a capacidade de promover o controle social. De acordo com a presidente do Conselho entrevistado, "[...] sozinho não, pode auxiliar no processo". Portanto, o Conselho pode auxiliar nas açóes voltadas ao controle social, mas para isso o mesmo conta com a assistência e a participação de outras entidades e espaços públicos no processo.

Nas açóes que o Conselho realiza ou pode vir a realizar para a promoção do controle social, pode-se evidenciar pelo trecho da entrevista que diz que "[...] mas isso não é só o conselho que decide, toda comunidade, nas audiências públicas e nas votaçóes [participa]". O que demonstra que o Comude pode participar e promover de açôes de controle social, mas depende da participação de outros espaços públicos.

O Quadro 2 apresenta uma síntese dos resultados obtidos a partir da entrevista realizada, no tocante a categoria de análise de controle social, e seus respectivos critérios de análise.

Em síntese, conforme observa-se no Quadro 2, o Comude tem acesso à informaçóes do setor público por meio do portal da transparência e de forma direta, pois alguns servidores públicos são membros do conselho. O Comude no escopo da sua atuação, não discute temas vinculados à transparência e combate à corrupção. 
Quadro 2: Resumo da categoria de análise controle social

\begin{tabular}{|c|c|c|c|}
\hline \multirow[t]{10}{*}{$\begin{array}{l}7- \\
\text { Controle } \\
\text { Social }\end{array}$} & \multirow{2}{*}{$\begin{array}{l}7.1 \text { - Transparência } \\
\text { (informaçôes governamentais } \\
\text { abertas aos cidadãos, } \\
\text { propiciando o acesso as } \\
\text { informaçóes possibilitando } \\
\text { uma maior fiscalizaçáo pela } \\
\text { sociedade) }\end{array}$} & $\begin{array}{l}\text { 7.1.1 - O Conselho tem acesso às } \\
\text { informaçóes do setor público? De que } \\
\text { forma? }\end{array}$ & $\begin{array}{l}\text { Sim, } \\
\text { conselheiros } \\
\text { funcionários } \\
\end{array}$ \\
\hline & & $\begin{array}{l}\text { 7.1.2 - Existem mecanismos que } \\
\text { permitam ao Conselho, acesso direto às } \\
\text { informaçôes governamentais? Quais? }\end{array}$ & Sim \\
\hline & \multirow[t]{3}{*}{$\begin{array}{l}7.2 \text { - Legitimidade Social } \\
\text { (reconhecimento da } \\
\text { capacidade de atuaçáo como } \\
\text { promotor do controle social) }\end{array}$} & $\begin{array}{l}\text { 7.2.1 - O Conselho, como promotor } \\
\text { do desenvolvimento local/regional, tem } \\
\text { condiçóes de assumir o protagonismo } \\
\text { do controle social na sua área de } \\
\text { atuaçáo? }\end{array}$ & $\begin{array}{l}\text { Não, } \\
\text { depende } \\
\text { de outros } \\
\text { fatores } \\
\end{array}$ \\
\hline & & $\begin{array}{l}\text { 7.2.2 - Os atores que compóem } \\
\text { o Conselho são reconhecidos pela } \\
\text { sociedade como agentes promotores do } \\
\text { bem comum? }\end{array}$ & $\begin{array}{l}\text { Deveriam, } \\
\text { mas náo são }\end{array}$ \\
\hline & & $\begin{array}{l}\text { 7.2.3 - A dinâmica do Conselho } \\
\text { permite espaço para discussão de temas } \\
\text { ligados à transparência e combate à } \\
\text { corrupção? }\end{array}$ & Não \\
\hline & $\begin{array}{l}\text { 7.3 - Acompanhamento } \\
\text { de Políticas Públicas - } \\
\text { (julgar os mecanismos de } \\
\text { acompanhamento das políticas } \\
\text { públicas) }\end{array}$ & $\begin{array}{l}\text { 7.3.1 - O Conselho acompanha e } \\
\text { divulga análises das políticas públicas? }\end{array}$ & Sim \\
\hline & $\begin{array}{l}7.4 \text { - Instrumentos de } \\
\text { Controle - (utilização } \\
\text { dos meios de controle } \\
\text { governamental de forma } \\
\text { independente) }\end{array}$ & $\begin{array}{l}\text { 7.4.1 - Quais instrumentos de controle } \\
\text { são utilizados pelo Conselho? }\end{array}$ & Não utiliza \\
\hline & $\begin{array}{l}7.5 \text { - Inteligibilidade } \\
\text { (capacidade de perceber e } \\
\text { compreender as informaçóes) }\end{array}$ & $\begin{array}{l}\text { 7.5.1 - As informaçóes disponibilizadas } \\
\text { ou acessadas pelo Conselho são } \\
\text { compreendidas pelos conselheiros? }\end{array}$ & Sim \\
\hline & \multirow{2}{*}{$\begin{array}{l}7.6 \text { - Promoção do controle } \\
\text { social - (Capacidade do } \\
\text { Conselho promover o controle } \\
\text { social) }\end{array}$} & $\begin{array}{l}\text { 7.6.1 - As açóes do Conselho tem a } \\
\text { capacidade promover o controle social? }\end{array}$ & Não sozinho \\
\hline & & $\begin{array}{l}\text { 7.6.2 - Quais açóes o Conselho realiza } \\
\text { e pode realizar para a promoção do } \\
\text { controle social? }\end{array}$ & Não realiza \\
\hline
\end{tabular}

Fonte: elaborado pelos autores a partir da entrevista.

Portanto, constata-se que as informaçóes acessadas e apresentadas são compreendidas pelos conselheiros. O Comude não possui possibilidades de sozinho promover o controle social, mas em parceria com outras entidades e instituiçóes pode auxiliar nas açóes voltadas ao controle social. 


\subsection{Análise da percepção do gestor público}

Esta seção aborda a entrevista realizada com o prefeito do município de São Valério do Sul, a qual teve como finalidade analisar o tratamento dado pelo Poder Executivo local às questóes relativas ao desenvolvimento regional, abordadas a partir da ótica da gestáo social. O gestor está no seu primeiro mandato como prefeito municipal.

Os pontos positivos ressaltados pelo gestor público em relação ao Comude do Município são importantes pelo “[...] envolvimento que ele agrega na comunidade, ele une a comunidade e reúne a comunidade, passa a planejar açóes em prol da própria comunidade, em prol do próprio cidadão". Este ponto destacado da entrevista demonstra o interesse do gestor público pela participação da sociedade nos espaços públicos existentes.

O gestor do município considerou como ponto negativo na atuação Comude que o mesmo "deveria fazer mais pressão para o governo repassar mais rápido, por que a gente tem um processo de votação das açóes que o município necessita, e fica na expectativa, a comunidade também, de receber no caso rápido o recurso".

Ao se referir do governo, o gestor se direciona ao Governo do Estado do Rio Grande do Sul, que realiza um processo de orçamento participativo ${ }^{7}$, para definir volume de investimentos a ser realizado pelo mesmo em cada região.

O gestor ressaltou que o Comude não interfere na definição de políticas públicas no seu município, mas acompanha e avalia ações e políticas públicas no município de São Valério do Sul, náo participando das prestaçóes de contas do poder executivo local.

O Comude, segundo o gestor realiza "só esse trabalho de esclarecimento na questão do PPC [Programa de Participação Popular e Cidadã], no caso, e no caso de entrosamento com as comunidades que deveriam ter um pouquinho mais, clarear mais para os munícipes, e para as pessoas das comunidades, qual é a real função do Comude”.

A gestão municipal não se utiliza das demandas discutidas e deliberadas no âmbito do Comude, para a definição e elaboração das políticas públicas da sua gestão, o que poderia aproximar a gestão municipal das demandas discutidas e deliberadas no âmbito do Comude.

O gestor apresenta uma percepção de que o funcionamento do Comude está vinculado às ações dos programas de participação popular oriundas da definição de demandas e políticas públicas do orçamento participativo do Estado do Rio Grande do Sul.

Esta situação limita a atuação deste espaço público de participação popular, pois tem em sua atuação apenas vinculação ao processo de escolha das políticas públicas vinculadas ao orçamento participativo.

\section{CONSIDERAÇÓES FINAIS}

Por meio deste estudo pode-se verificar, avaliar e analisar as dinâmicas existentes no âmbito do Conselho Municipal de Desenvolvimento (Comude) de São Valério do Sul, no

7 Para maiores informaçóes, pesquisar dentre outras referências, em Allebrandt (2010), Lüchmann (2002). 
tocante a participação popular e as ações voltadas ao controle social sobre o desenvolvimento local e regional.

A transparência dos atos da administração local no âmbito do Comude, de acordo com a percepçáo do presidente entrevistado acontece, mas a mesma ocorre principalmente pelo fato de que alguns funcionários públicos municipais são membros do Comude.

A transparência entre a gestão pública e os conselhos deveria acontecer independentemente da condição dos representantes do Conselho, isto fortaleceria a atuação dos conselheiros no âmbito do seu escopo.

No intuito de aperfeiçoar e qualificar a atuaçáo do Conselho na comunidade local e regional, o mesmo deveria dispor de espaços para discussão de temas ligados a transparência e o combate a corrupção, pois no momento inexiste tal espaço.

Constatou-se também que o Comude acompanha e divulga políticas públicas, sendo este um objetivo de grande importância ao funcionamento do mesmo, e para a correta implementação de políticas públicas e alocação de recursos públicos.

Observa-se que o Comude não realiza açóes com a finalidade de promover do controle social na sua área de atuação. Na concepção da presidente do Comude entrevistada, também não possui capacidade de promovê-lo de forma independente, pois para isso, necessitaria do auxílio de outras entidades, conselhos e atores sociais para promover o controle social.

O gestor do município de São Valério do Sul, destaca a importância da atuação do Comude quanto a sua potencialidade de propiciar um maior envolvimento entre os cidadãos. $\mathrm{O}$ mesmo destaca que não são utilizadas as açóes discutidas e deliberadas nos processos participativos do Comude.

Observa-se pela entrevista do prefeito do município que o Comude desempenha suas atividades, basicamente vinculadas ao Programa de Participação Popular e Cidadã do Estado do Rio Grande do Sul. Tal situação, restringe a atuação do Conselho, pois o mesmo deveria ser um espaço de discussão amplo e irrestrito dos assuntos relacionados ao desenvolvimento local e regional.

Quanto as limitaçóes observadas neste estudo, destaca-se que utilizou-se o Comude como objeto de pesquisa quanto a temática do controle social. Em estudos posteriores, podem ser realizados estudos em outros conselhos setoriais, bem como com os cidadãos que não participam de nenhum conselho setorial.

Apesar de este estudo abordar uma análise a partir da percepção da entrevista realizada com o presidente do Comude e com o prefeito do município de São Valério do Sul, os resultados apontam para a importância do Conselho na participação popular e nas ações de controle social. Evidenciam também a necessidade de qualificação destes processos, espaços públicos, e principalmente aos cidadãos que participam do mesmo.

\section{REFERÊNCIAS}

ALLEBRANDT, S. L. A participaçáo da sociedade na gestão pública. Ijuí: Ed. Unijuí, 2002. 
. Cidadania e gestáo do processo de desenvolvimento: um estudo sobre a

atuação dos conselhos regionais e municipais de desenvolvimento do Rio Grande do Sul, de 1990 a 2009. 302 f. Tese (Doutorado em Desenvolvimento Regional) - Universidade de Santa Cruz do Sul, 2010.

Os conselheiros municipais. In.: TENÓRIO, F. G.; KRONEMBERGER, T. S

(Orgs.). Gestáo Social e Conselhos gestores. 1a ed. Rio de janeiro: FGV Editora, 2016. p. 207-230.

ALLEBRANDT, Sérgio L.; SIEDENBERG, Dieter R. A experiência dos Coredes no Rio Grande do Sul: uma análise à luz da gestáo social e da cidadania deliberativa. In: DALLABRIDA, Valdir R. (Org.). Governança territorial e desenvolvimento: Descentralização político-administrativa, estruturas subnacionais de gestão do desenvolvimento e capacidades estatais. Rio de Janeiro: Garamond, 2011.

BERGUE, S. T. Escolas de governo e fomento ao controle social: o caso do programa É da Nossa Conta. 2012. Disponível em <http://www1.tce.rs.gov.br/portal/page/portal/ tcers/institucional/esgc/biblioteca_eletronica/artigos/Artigo\%20CLAD\%202012.pdf>. Acesso em 21 jan. 2016.

BÜTTENBENDER, Pedro L.; SIEDENBERG, Dieter R.; ALLEBRANDT, Sérgio L. Coredes: Estruturação, articulações intra e inter-regionais, referenciais estratégicos e consideraçóes críticas. In: DALLABRIDA, Valdir R. (Org.). Governança territorial e desenvolvimento: Descentralização político-administrativa, estruturas subnacionais de gestão do desenvolvimento e capacidades estatais. Rio de Janeiro: Garamond, 2011.

CANÇADO, Airton C.; PEREIRA, José R; TENÓRIO, Fernando G. Gestão social: epistemologia de um paradigma. 2o Ed. Curitiba: CRV, 2015.

ESQUIVEL-CORELLA, F. Gerencia Social: un análisis crítico desde el Trabajo Social. 1. ed. Buenos Aires: Espacio, 2005.

ESQUIVEL-CORELLA, F. Trabajo Social y Gerencia Social: una revisión teórico-crítica de sus vínculos. Política Social y Trabajo Social, San Juan, Puerto Rico: Universidad de Puerto Rico, n. 2, 2004. p. 120-134.

FEE, Fundação de Economia e Estatística Siegfried Emanuel Heuser. FEE Mapas. Disponível em <http://www.fee.rs.gov.br/perfil-socioeconomico/coredes/ detalhe/?corede=Celeiro $>$. Acesso em 08 abr. 2016, 2011.

FISCHER, T. et al. Perfis visíveis na gestão social do desenvolvimento. Revista de Administraçáo Pública (RAP), Rio de Janeiro, v. 40, n. 5, p. 789-808, Set./Out. 2006. 
FRANÇA FILHO, G. C. de. Definido gestão social. In: SILVA JÚNIOR, J. T.; MÂISH, R. T.; CANÇADO, A. C. (Ed.). Gestáo social: práticas em debate, teorias em construção. Fortaleza: UFC, 2008. p. 27-37.

GOMES, E. G. M. Conselhos gestores de políticas públicas: aspectos teóricos sobre o potencial de controle social democrático e eficiente. Cadernos Ebape, v. 13, no 4, 2015.

KLIKSBERG, B. ¿Cómo formar gerentes sociales? Elementos para el diseño de estrategias. In: KLIKSBERG, B.; FALETTO, E. ¿Como enfrentar la pobreza?: estrategias y experiencias organizacionales innovadoras. Buenos Aires, Ar.: Grupo Editor Latinoamericano, 1989. p. 131-145.

KLIKSBERG, B. Gerencia social: una revisión de situación. Administración y Desarrollo, n. 29, Santa Fe de Bogotá, Dez. 1988, p. 9-23.

LAISNER, R. C.; DE MARIO, C. G. Os desafios da avaliação de políticas públicas como instrumento estratégico de gestão e de controle social. Revista de Políticas Públicas, vol. 18, núm. 2, p. 619-630, 2014.

\section{LÜCHMANN, Lígia H. H. Possibilidades e limites da democracia deliberativa:}

a experiência do orçamento participativo de Porto Alegre. 226f. Tese (Doutorado em Ciência Política) - IFCH, Unicamp, Campinas, 2002.

PAULA, A. P. P. de. Por uma nova gestão pública: limites e potencialidades da experiência contemporânea. Rio de Janeiro: Editora FGV, 2005 a.

Administração pública brasileira entre o gerencialismo e a gestão social. RAE, vol. 45, núm. 1, 2005b.

PNUD. Programa das Nações Unidas para o Desenvolvimento.Atlas do

Desenvolvimento Humano. Disponível em < http:/www.pnud.org.br/atlas/ranking/ Ranking-IDHM-Municipios-2010.aspx >. Acesso em 02 jul. 2016, 2013.

SÃO VALÉRIO DO SUL. Portal de legislação. Disponivel em < http://www. saovaleriodosul.rs.gov.br/137/Legislacao/>. Acesso em 02 jul. 2016.

SERRA, R. de C. C.; CARNEIRO, R. Controle social e suas interfaces com os controles interno e externo no Brasil contemporâneo. Espacios Públicos, vol. 15, núm. 34, p. 4364, mai./ago. 2012.

SINGER, P. Alternativas da gestão social diante da crise do trabalho. In: RICO, E. de M.; RAICHELIS, R. (Orgs.). Gestáo Social: uma questão em debate. São Paulo: Educ/IEE/ PUCSP, 1999. p. 55-66. 
TENÓRIO, F. G.. Gestão social: uma perspectiva conceitual. 1998. Disponível em<http://bibliotecadigital.fgv.br/ojs/index.php/rap/article/viewFile/7754/6346.> Acesso em 26 out. 2015.

. (Re)visitando o conceito de gestão social. Desenvolvimento em Questão, Ijuí, RS, v. 3, n. 5, jan./jun. 2005. p. 101-124.

. Um espectro ronda o terceiro setor, o espectro do mercado: ensaios de gestáo social. 3. Ed. Revista e ampliada. Ijuí: Editora Unijuí, 2008.

. Descentralização político-administrativa, gestão social e participação cidadã. In: DALLABRIDA, Valdir R (Org.). Governança territorial e desenvolvimento: descentralização político-administrativa, estruturas subnacionais de gestão do desenvolvimento e capacidades esetatais. Rio de Janeiro: Garamond, 2011.

- Gestão social, um conceito não idêntico? Ou a insuficiência inevitavel do pensamento. In: CANÇADO, Airton C.; SILVA JR, J. T.; TENÓRIO, Fernando G. (Orgs) Gestáo social: aspectos teóricos e aplicaçóes. Ijuí: Editora Unijuí, 2012a.

Escopo teórico. In: TENÓRIO, Fernando G. (Org.) Cidadania e

desenvolvimento local: critérios e análise. Rio de Janeiro: Editora FGV, 2012b.

. Gestão social: conceito. In.: TENÓRIO, F. G.; KRONEMBERGER, T. S

(Orgs.). Gestáo Social e Conselhos gestores. $1^{\text {a }}$ ed. Rio de janeiro: FGV Editora, 2016. p. 13-34.

THOMPSON, John B. Ideologia e Cultura Moderna - teoria social crítica na era dos meios de comunicação de massa. Tradução do Grupo de Estudos sobre Ideologia, comunicação e representações sociais da pós-graduação do Instituto de Psicologia da PUCRS. Petrópolis: Vozes, 1995.

VILLELA, Lamounier E. Escopo metodológico. In: TENÓRIO, Fernando G. (Org.) Cidadania e desenvolvimento local: critérios e análise. Rio de Janeiro: Editora FGV, 2012. 